\title{
Relative Body Mass Index as a New Tool for Nutritional Status Assessment in Children and Adolescents with Bronchial Asthma
}

DOI: $10.17691 / \mathrm{stm} 2017.9 .1 .18$

Received May 26, 2016

T.I. Eliseeva, MD, PhD, Associate Professor, Department of Hospital Pediatrics';

N.A. Geppe, MD, DSc, Professor, Head of the Department of Children's Diseases;

S.K. Ignatov, DSc, Professor, Department of Photochemistry and Spectroscopy;

S.K. Soodaeva, MD, DSc, Professor, Head of the Laboratory of Clinical and Experimental Biophysics 4 ; Professor, Department of Human Pathology, Institute of Professional Education;

E.V. Tush, MD, PhD, Associate Professor, Department of Hospital Pediatrics';

O.V. Khaletskaya, MD, DSc, Professor, Head of the Department of Hospital Pediatrics";

T.E. Potemina, MD, DSc, Professor, Head of the Department of Pathologic Physiology";

A.B. Malakhov, MD, DSc, Professor, Department of Children's Diseases;

N.I. Kubysheva, DSc, Researcher, Postdoctoral Training Department, Scientific Computing Center ${ }^{5}$;

Senior Researcher ${ }^{6}$;

V.D. Solovyov, DSc, Professor, Leading Researcher ${ }^{6}$

${ }^{1}$ Nizhny Novgorod State Medical Academy, 10/1 Minin and Pozharsky Square, Nizhny Novgorod, 603005,

Russian Federation;

2I.M. Sechenov First Moscow State Medical University, 8/2 Trubetskaya St., Moscow, 119991,

Russian Federation;

${ }^{3}$ Lobachevsky State University of Nizhni Novgorod, 23 Prospekt Gagarina, Nizhny Novgorod, 603950,

Russian Federation;

${ }^{4}$ Pulmonology Research Institute, Federal Biomedical Agency of Russian Federation, 32, $11^{\text {th }}$ Parkovaya St.

Moscow, 105077, Russian Federation;

${ }^{5}$ Centro de Investigación en Computación, Instituto Politécnico Nacional (CIC-IPN), Av. Juan de Dios Bátiz,

Esq. Miguel Othón de Mendizábal S/N, Gustavo A. Madero, 07738, D.F., México;

${ }^{6}$ Kazan Federal University, 18 Kremlyovskaya St., Kazan, Republic of Tatarstan, 420008, Russian Federation

The aim of the investigation was to estimate the possibilities of using relative body mass index (RBMI) for determining age- and gender-specific aspects of nutritional status in children and adolescents with bronchial asthma (BA) of different severity degrees.

Materials and Methods. The study involved 887 children and adolescents with BA of different severities, aged 5-17 years (61215 months), of them 655 were boys. Their body mass index (BMI) was evaluated based on the Z-score criterion and nutritional status was determined as recommended by the World Health Organization (WHO). To unify nutritional status assessment in patients of different age and gender groups, there was introduced RBMI representing the ratio of the patient's BMI to gender- and age-specific median BMI value presented in the WHO reference data.

Results. Nutritional status and its relation to BA were studied in children and adolescents using two parameters: the standard nutritional status indicator based on BMI Z-scores as recommended by WHO, and a new parameter, RBMI, representing the ratio of the patient's BMI to gender- and age-specific median BMI value recommended by WHO. No significant nutritional status differences were found in the studied sample of patients with various degrees of BA severity. There was revealed a tendency to a decrease in the proportion of children with normal body weight and an increase in the proportion of overweight children as BA severity increased, $\chi^{2}=26.82 ; p=0.08$.

Conclusion. Using RBMI for assessment of BA patients makes it possible to significantly facilitate clinical data analysis and obtain new data unavailable when standard parameters are applied.

Key words: bronchial asthma; nutritional status of children; obesity in asthma; body mass index; relative body mass index.

At present, the aim of bronchial asthma (BA) therapy is to achieve control over the disease signs, progression and recurrence risk factors. It is recognized that BA can be controlled in all patients, this fact being emphasized in the international consensus papers, including GINA 2016 [1]. However, the present-day methods of BA therapy fail to provide adequate control in some patients [2-4]. In recent years, great attention is paid to personified

For contacts: Tatyana I. Eliseeva, e-mail: eliseevati@yandex.ru 
approach to BA treatment with regard to the disease phenotype and comorbid conditions able to influence BA progression in a particular patient $[5,6]$. Patients' nutritional status impairments, especially overweight and obesity, occupy an important place in the list of diseases potentially able to affect adversely BA progression $[7,8]$.

According to the report of the World Health Organization (WHO) for 2015, the incidence of overweight in the population of children under 5 years of age around the world equals $6.3 \%$, it is $12.4 \%$ in the European population. Among the children of the European region aged 11 to 13 years, overweight occurs in 5 to $25 \%$. Overweight is reported to be found among boys more often than among girls [9]. According to the results of epidemiologic studies conducted in Russia for the period of 2005-2006 and including the data on 10,223 adolescents aged 12-17, the incidence of overweight among them equaled $11.8 \%$, obesity $2.3 \%$ [10]. The same studies show that in Nizhny Novgorod there were observed $10.8 \%$ of overweight adolescents aged 12-17, among them $2 \%$ with obesity. In recent years, in some regions of Russia, there is a tendency towards an increase in the incidence of overweight and obesity among children and adolescents [11].

Overweight and obesity are defined as the presence of excessive and abnormal body fat which may cause health damage. These can be estimated by means of several indicators, including body mass index (BMI), the content of fat in the body and also anthropometric indexes [9]. Today, BMI is considered as the main screening tool for nutritional status assessment and is defined as weight in kilograms divided by the square of height in meters [9].

Numerous studies demonstrate the relationship between BA, increasing body weight and obesity in adults [12, 13]. Most of the authors have found the existence of association between obesity and asthma in children as well [14-18]. However, this opinion is not shared by everyone. Some researchers note that the relationship between obesity and BA severity has not been proved [12, 19-21]. There are works demonstrating positive influence of body weight loss on BA character in children [22]. In Russia, a few works concerning nutritional status of children with BA evidence that there is a tendency to body weight gain in patients with BA from childhood [23].

Ambiguity of research findings aiming to reveal the links between obesity and asthma in pediatric and adolescent population can be caused by several reasons. On the one hand, regional peculiarities of nutritional status and asthma incidence, social differences, behavioral and eating habits may play a role. On the other hand, there are certain difficulties in studying nutritional status in children of various age and gender groups, for which there are specific BMI standards and forming combined BMl-based groups in children, unlike in adults, requires development of additional methodological approaches. In particular, the groups under study should be divided into homogeneous subgroups, each of them having specific quantile BMI values published by $\mathrm{WHO}[9]$. Since the age in the WHO tables is given in life months, the number of groups of the same age during the period from 5 to 17 years is 156 for each gender. This reduces the possibilities of nutritional status assessment in children and adolescents, complicates comparing the children from various age groups and finding common patterns because obtaining statistically significant results requires repeated increase in a cohort of patients.

Introducing a parameter that will unify BMI values for various age and gender groups can serve as a solution of this problem. We suggest using relative body mass index (RBMI), i.e. the ratio of the measured $\mathrm{BMI}$ to gender- and age-specific median BMI value taken from the WHO tables, as such parameter [9]:

\section{$\mathrm{RBMI}=\mathrm{BMI} /$ median $\mathrm{BMI}$ value.}

We believe that using this value in addition to BMI assessment provides the possibility to improve informativeness of nutritional status analysis in BA children and adolescents and to obtain the parameters which are impossible to determine based on BMI only.

The aim of the investigation was to estimate the possibilities of using relative body mass index for determining age- and gender-specific aspects of nutritional status in children and adolescents with bronchial asthma of different severity degrees.

Materials and Methods. We conducted a retrospective analysis of data on studying the patients with atopic BA aged 5 (61 months) to 17 years (215 months), mean age 10.9 \pm 3.7 years (134.7 \pm 45.3 months), staying in Children City Clinical Hospital No.1, Nizhny Novgorod, during 2008 to 2012. The study included a total of 887 children and adolescents with atopic BA, of them there were 655 boys and 232 girls (Table 1). All the children underwent standard examination in a clinical setting, including anthropometry. The diagnosis of BA and the disease severity were established by an

Table 1

Clinical profile of subjects

\begin{tabular}{lcc}
\hline \multicolumn{1}{c}{ Characteristic } & $\begin{array}{c}\text { Number } \\
\text { of patients } \\
(\mathbf{n}=887)\end{array}$ & $\begin{array}{c}\text { Gender } \\
\text { (boys/girls) } \\
(\mathrm{n}=655 / 232)\end{array}$ \\
\hline Age (years): & 162 & \\
$\quad 5-6$ & 173 & $95 / 67$ \\
$7-9$ & 208 & $111 / 62$ \\
$10-12$ & 142 & $163 / 45$ \\
$13-14$ & 202 & $117 / 25$ \\
15-17 & & \\
Degree of bronchial asthma severity: & 101 & $84 / 17$ \\
intermittent & 447 & $328 / 119$ \\
mild persistent & 277 & $196 / 81$ \\
moderate persistent & 62 & $47 / 15$ \\
$\quad$ severe persistent & & \\
\hline
\end{tabular}


attending doctor in accordance with recommendations valid at that period of time (GINA 2006-2011) [24-26]. Mild intermittent BA was diagnosed in 101 patients, mild persistent BA in 447 patients, moderately severe BA was found in 277 children and 62 patients had severe BA.

The study was performed following approval by the Ethics Committees of I.M. Sechenov First Moscow State Medical University and Nizhny Novgorod State Medical Academy. Written informed consent was obtained from every patient aged 15-17 years and from the parents of those under 15 years of age, in accordance with "The Basic Law on Health Protection of the Citizens of the Russian Federation" No.5487-1 dated July 22, 1993.

Basic anthropometric indicators, including the child's weight in kilograms and height in centimeters, were measured in all children; BMl was calculated using the formula "weight/squared height" $\left(\mathrm{kg} / \mathrm{m}^{2}\right)$. The children's BMI with regard to their gender and age was assessed using Z-score criteria recommended by WHO [9]. Correspondence of the child's BMI to the median BMI values in the range of Z-scores from -1 to +1 was considered to be normal nutritional status, the range from +1 to +2 was defined as elevated BMI (overweight), elevation of the median BMI value by over 2 Z-scores was regarded as obesity. BMI values in the range of Z-scores from -1 to -2 was considered to be underweight, BMI reduced by over 2 units was regarded as severe body weight deficit [9].

RBMI, unlike BMI, is a quantitative indicator which already implies adjustment for the child's age and gender and characterizes the patient's nutritional status comprehensively. The values of this coefficient, corresponding to nutritional status groups consistent with Z-score evaluation system, obtained in the present study, are shown in Table 2.

RBMI distribution for seven groups of patients grouped according to BMI-based Z-scores (Figure 1) showed that there was statistically significant difference between the groups $(p<0.0001)$.

Table 2

Mean values of relative body mass index grouped according to the patients' nutritional status determined previously using Z-score system

\begin{tabular}{lcccccccc}
\hline \multirow{2}{*}{ Groups } & \multicolumn{7}{c}{ Body mass index values } \\
& $<-3 Z$ & $<-2 Z$ & $<-1 Z$ & Median $\pm 1 Z$ & $>1 Z$ & $>2 Z$ & $>3 Z$ \\
Combined group of patients (absolute number): & 7 & 17 & 113 & 493 & 177 & 71 & 9 \\
$\quad$ mean \pm SD & $0.69 \pm 0.05$ & $0.79 \pm 0.03$ & $0.86 \pm 0.03$ & $1.01 \pm 0.06$ & $1.21 \pm 0.06$ & $1.40 \pm 0.10$ & $1.63 \pm 0.21$ \\
95\% Cl & $0.66-0.73$ & $0.77-0.81$ & $0.85-0.87$ & $1.00-1.01$ & $1.20-1.21$ & $1.39-1.42$ & $1.60-1.66$ \\
\hline Boys (absolute number): & 5 & 13 & 77 & 361 & 137 & 56 & 6 \\
$\quad$ mean \pm SD & $0.60 \pm 0.04$ & $0.79 \pm 0.04$ & $0.87 \pm 0.03$ & $1.01 \pm 0.06$ & $1.21 \pm 0.07$ & $1.42 \pm 0.10$ & $1.67 \pm 0.25$ \\
$95 \%$ Cl & $0.66-0.73$ & $0.77-0.82$ & $0.86-0.88$ & $1.00-1.01$ & $1.20-1.22$ & $1.41-1.43$ & $1.63-1.71$ \\
\hline Girls (absolute number): & 2 & 4 & 36 & 132 & 40 & 15 & 3 \\
mean \pm SD & $0.70 \pm 0.06$ & $0.78 \pm 0.02$ & $0.86 \pm 0.03$ & $1.00 \pm 0.06$ & $1.18 \pm 0.06$ & $1.34 \pm 0.09$ & $1.54 \pm 0.05$ \\
$95 \%$ Cl & $0.64-0.76$ & $0.74-0.83$ & $0.84-0.87$ & $1.00-1.01$ & $1.17-1.20$ & $1.32-1.36$ & $1.49-1.59$ \\
\hline
\end{tabular}

H e r e: SD — standard deviation; $\mathrm{Cl}$ — confidence interval; $F=224.59 ; p<0.0001$.

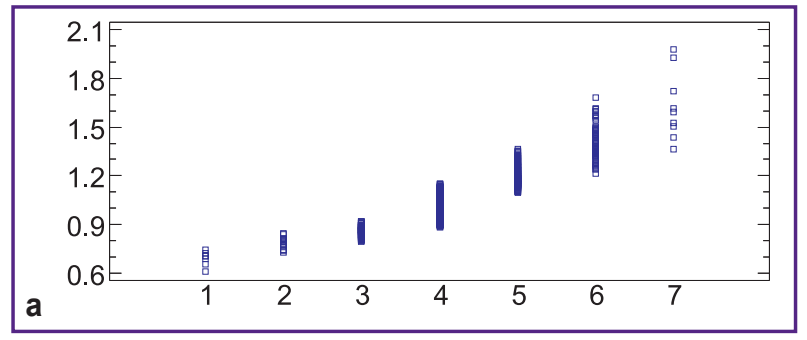

Figure 1. Relative body mass index of examined patients with bronchial asthma, grouped relying on BMI-based Z-score values: (a) in the combined group of patients; (b) in the group of boys; (c) in the group of girls. Horizontal axis: numbers of groups formed according to body mass index values, vertical axis: relative body mass index
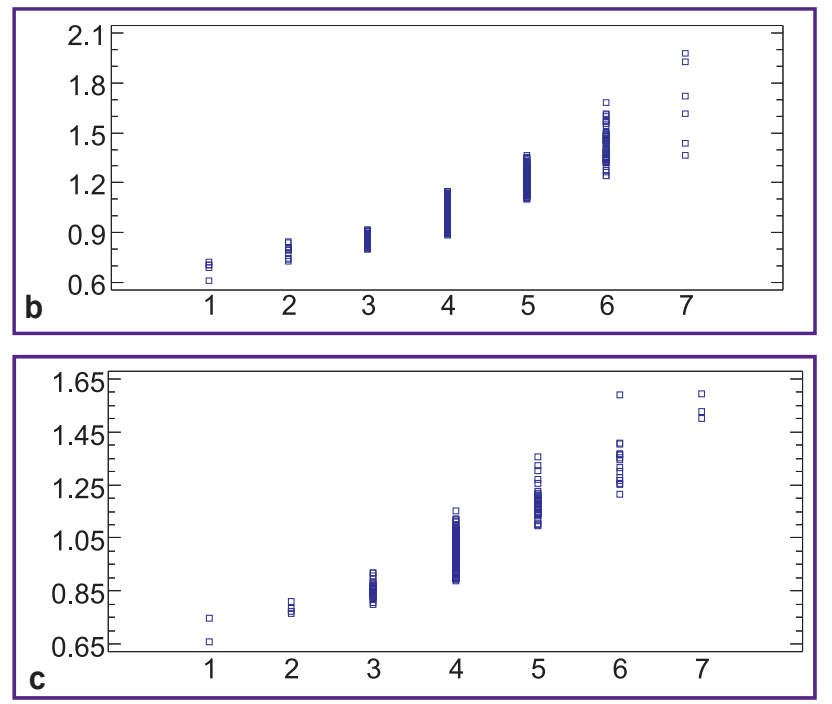
The data are presented in absolute and relative units, $\mathrm{M} \pm \mathrm{m}$, where $\mathrm{M}$ - arithmetic mean, $\mathrm{m}$ - standard deviation, confidence interval of $95 \%$ shown. Statistical criteria $x^{2}$, ANOVA, Student t-test, Kruskal-Wallis test were used for analysis. Statistical calculations were carried out using Statgraphics Plus v. 5 software. The differences were considered statistically significant at $p<0.05$.

\section{Results}

Evaluation of nutritional status in patients with bronchial asthma based on body mass index. Over half of children, $55.6 \%$ (493/887), studied had normal BMI values (BMI median $\pm 1 Z$ ) (Table 3, Figure 2). With BA severity increasing, the proportion of patients having normal BMI values progrediently decreased. BMI reduction was noticed in $15.6 \%$ of patients $(137 / 887)$, including a few children $(2.7 \%, 24 / 887)$ whose BMI was reduced to extreme values (lower than $-2 Z$ ). Overweight, including obesity, was revealed in a considerable number of patients, $29.3 \%$ (257/887), with obesity diagnosed in $9.0 \%$ of patients $(80 / 887)$, significantly exceeding population indices [10].

Nutritional status differences in patients with BA of different severities appear to be a tendency, $X^{2}=26.82$; $p=0.08$. No distinct gender differences in nutritional status of patients with different BA severities were revealed based on BMI analysis (Table 4). However, a big correlation between nutritional status and BA severity in boys is noteworthy $\left(X^{2}=28.66 ; p=0.053\right)$ as compared to girls $\left(x^{2}=8.76 ; p=0.97\right)$ : in boys, such dependence proves to be a pronounced tendency, though it is not observed in girls.

Analysis of allocating the patients to groups by BMI, age and gender (Table 5, Figure 3) demonstrates statistically significant differences between different age groups $\left(x^{2}=24.0 ; p=0.01\right)$. The given results show that in general, overweight is observed more often in pre-school, early school-aged and pre-pubertal BA

Table 3

Distribution of patients (absolute number/\%) with different bronchial asthma severities based on body mass index values assessed according to Z-score system $(W H O)\left(X^{2}=26.82 ; p=0.08\right)$

\begin{tabular}{|c|c|c|c|c|c|c|c|c|}
\hline \multirow{2}{*}{$\begin{array}{c}\text { Bronchial asthma } \\
\text { severity }\end{array}$} & \multicolumn{8}{|c|}{ BMI parameters (Z-score values) } \\
\hline & Lower than -3 & From -3 to -2 & From -2 to -1 & From -1 to 1 & From 1 to 2 & From 2 to 3 & Higher than 3 & Total \\
\hline Intermittent & $1 / 1.0$ & $1 / 1.0$ & $10 / 9.9$ & $67 / 66.3$ & $15 / 14.9$ & $7 / 6.9$ & $0 / 0$ & $101 / 100$ \\
\hline Mild persistent & $4 / 0.9$ & $13 / 2.9$ & $53 / 11.9$ & $256 / 57.3$ & $89 / 19.9$ & $27 / 6.0$ & $5 / 1.1$ & $447 / 100$ \\
\hline Moderate persistent & $1 / 0.4$ & $3 / 1.1$ & $40 / 14.4$ & $143 / 51.6$ & $54 / 19.5$ & $32 / 11.6$ & $4 / 1.4$ & $277 / 100$ \\
\hline Severe persistent & $1 / 1.6$ & $0 / 0$ & $10 / 16.1$ & $27 / 43.6$ & $19 / 30.6$ & $5 / 8.1$ & $0 / 0$ & $62 / 100$ \\
\hline Total in the group & $7 / 0.8$ & $17 / 1.9$ & $113 / 12.7$ & $493 / 55.6$ & $177 / 20.0$ & $71 / 8.0$ & $9 / 1.0$ & $877 / 100$ \\
\hline
\end{tabular}

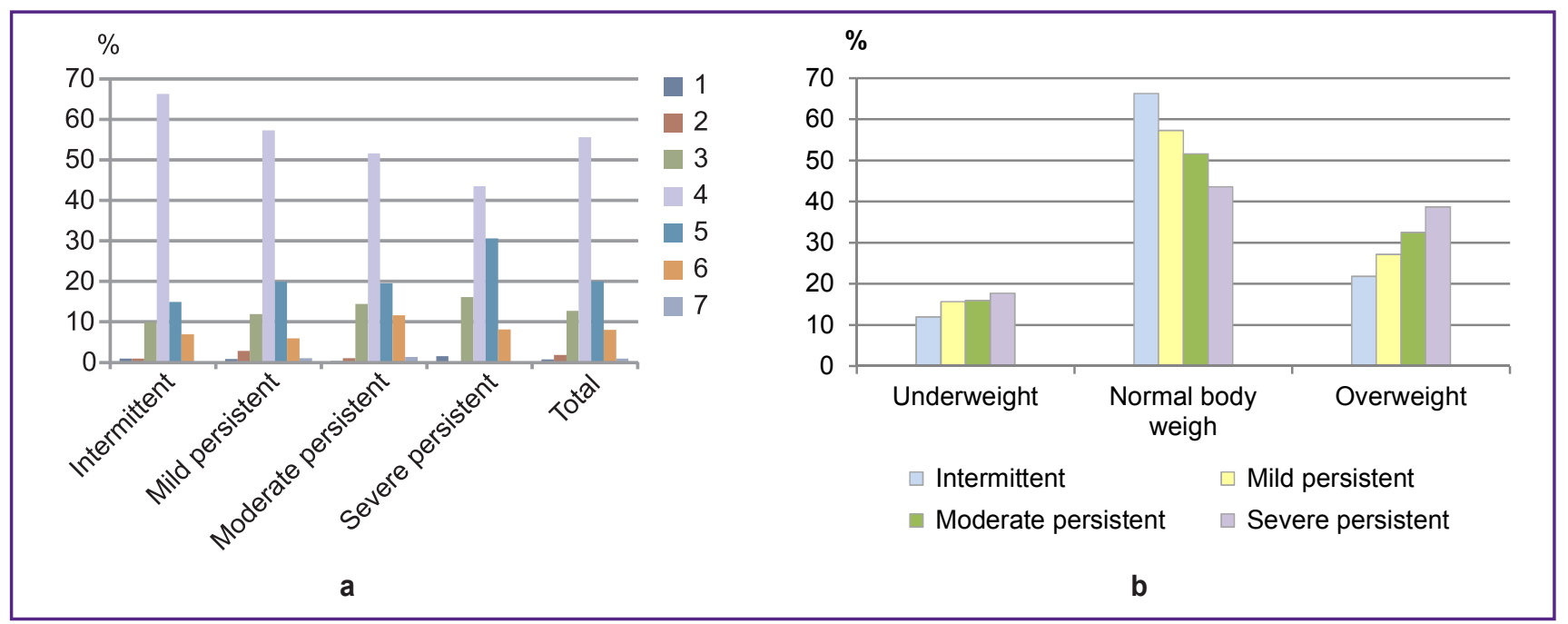

Figure 2. Distribution of children based on bronchial asthma severity and nutritional status: (a) a proportion of children with various body mass indices according to Z-score system among the children with different disease severities (the numbers by the color marks mean Z-score values: 1 - lower than $-3 ; 2-$ from -3 to $-2 ; 3-$ from -2 to $-1 ; 4-$ from -1 to $1 ; 5-$ from 1 to 2; 6 - from 2 to 3; 7 - higher than 3); (b) a proportion of children with different bronchial asthma severities among the patients with reduced, normal and increased body mass indices 
Table 4

Age and gender distribution of patients (absolute number/\%) with different bronchial asthma severities based on body mass index values assessed according to Z-score system (WHO)

\begin{tabular}{|c|c|c|c|c|c|c|}
\hline $\begin{array}{l}\text { Bronchial asthma } \\
\text { severity }\end{array}$ & Gender & Underweight & $\begin{array}{l}\text { Normal body } \\
\text { weight }\end{array}$ & Overweight & Statistics & Total \\
\hline \multirow[t]{2}{*}{ Total in the group } & Boys & $95 / 14.5$ & $361 / 55.1$ & $199 / 30.4$ & \multirow{2}{*}{$\begin{array}{l}x^{2}=3.71 \\
p=0.16\end{array}$} & $655 / 100$ \\
\hline & Girls & $42 / 18.1$ & $132 / 56.9$ & $58 / 25.0$ & & $232 / 100$ \\
\hline \multirow[t]{2}{*}{ Intermittent } & Boys & $11 / 13.1$ & $55 / 65.5$ & $18 / 21.4$ & \multirow{2}{*}{$\begin{array}{l}x^{2}=0.53 \\
p=0.77\end{array}$} & $84 / 100$ \\
\hline & Girls & $1 / 5.9$ & $12 / 70.6$ & $4 / 23.5$ & & $17 / 100$ \\
\hline \multirow[t]{2}{*}{ Mild persistent } & Boys & $49 / 14.9$ & $184 / 56.1$ & $95 / 28.9$ & \multirow{2}{*}{$\begin{array}{l}x^{2}=2.51 \\
p=0.28\end{array}$} & $328 / 100$ \\
\hline & Girls & $21 / 17.7$ & $72 / 60.5$ & $26 / 22.8$ & & $119 / 100$ \\
\hline \multirow[t]{2}{*}{ Moderate persistent } & Boys & $26 / 13.3$ & $105 / 53.6$ & $65 / 33.2$ & \multirow{2}{*}{$\begin{array}{l}x^{2}=3.94 \\
p=0.14\end{array}$} & $196 / 100$ \\
\hline & Girls & $18 / 22.2$ & $38 / 46.9$ & $25 / 30.9$ & & $81 / 100$ \\
\hline \multirow[t]{2}{*}{ Severe persistent } & Boys & $9 / 19.6$ & $17 / 37.0$ & $21 / 45.7$ & \multirow{2}{*}{$\begin{array}{l}x^{2}=4.43 \\
p=0.10\end{array}$} & $46 / 100$ \\
\hline & Girls & $2 / 13.3$ & $10 / 66.7$ & $3 / 20.0$ & & $15 / 100$ \\
\hline
\end{tabular}

Table 5

Age and gender distribution of bronchial asthma patients based on body mass index values assessed according to Z-score system (WHO)

\begin{tabular}{|c|c|c|c|c|c|c|c|c|c|}
\hline \multirow{2}{*}{$\begin{array}{l}\text { Age groups } \\
\text { (years) }\end{array}$} & \multirow{2}{*}{ Gender } & \multirow{2}{*}{ Total } & \multicolumn{3}{|c|}{ Absolute values } & \multirow{2}{*}{ Total } & \multicolumn{3}{|c|}{ Relative values (\%) } \\
\hline & & & Underweight & Median & Overweight & & Underweight & Median & Overweight \\
\hline \multirow{4}{*}{$5-6$} & All & 162 & 22 & 89 & 51 & 100 & 13.58 & 53.94 & 31.48 \\
\hline & Boys & 95 & 13 & 57 & 25 & 100 & 13.68 & 60.00 & 26.32 \\
\hline & Girls & 67 & 9 & 32 & 26 & 100 & 13.43 & 47.76 & 38.81 \\
\hline & & \multicolumn{8}{|c|}{$x^{2}=3.02 ; p=0.22$} \\
\hline \multirow{4}{*}{$7-9$} & All & 173 & 20 & 92 & 61 & 100 & 11.56 & 52.27 & 35.26 \\
\hline & Boys & 111 & 13 & 57 & 41 & 100 & 11.71 & 51.35 & 36.94 \\
\hline & Girls & 62 & 7 & 35 & 20 & 100 & 11.29 & 56.45 & 32.26 \\
\hline & & \multicolumn{8}{|c|}{$x^{2}=0.45 ; p=0.8$} \\
\hline \multirow{4}{*}{$10-12$} & All & 208 & 38 & 102 & 68 & 100 & 18.27 & 49.04 & 32.62 \\
\hline & Boys & 163 & 28 & 74 & 61 & 100 & 17.18 & 45.40 & 37.42 \\
\hline & Girls & 45 & 10 & 28 & 7 & 100 & 22.22 & 62.20 & 15.55 \\
\hline & & \multicolumn{8}{|c|}{$x^{2}=7.68 ; p=0.02$} \\
\hline \multirow{4}{*}{$13-14$} & All & 142 & 19 & 88 & 35 & 100 & 13.38 & 62.00 & 24.65 \\
\hline & Boys & 117 & 11 & 73 & 33 & 100 & 9.40 & 62.34 & 28.21 \\
\hline & Girls & 25 & 8 & 15 & 2 & 100 & 32.00 & 60.00 & 8.00 \\
\hline & & \multicolumn{8}{|c|}{$x^{2}=11.29 ; p=0.004$} \\
\hline \multirow{4}{*}{$15-17$} & All & 202 & 38 & 122 & 42 & 100 & 18.81 & 60.40 & 20.79 \\
\hline & Boys & 169 & 30 & 100 & 39 & 100 & 17.75 & 59.17 & 23.08 \\
\hline & Girls & 33 & 8 & 22 & 3 & 100 & 24.24 & 66.67 & 9.09 \\
\hline & & \multicolumn{8}{|c|}{$X^{2}=8.98 ; p=0.18$} \\
\hline
\end{tabular}

patients. In pubertal and adolescent age, increase in the proportion of BA patients with normal body weight is observed, while the proportion of overweight BA patients decreases.

More than half of boys under study had normal BMI values (BMI median $\pm 1 Z$ ) $-55.1 \%$ (361/655). In 14.5\%
(95/655), BMI was found to be reduced, in particular, reduction to the range from -1 to -2 Z-scores was noticed in $11.8 \%$ of patients $(77 / 655)$, in $2 \%$ of patients $(13 / 655)$ there was significant reduction to the range from $-2 Z$ to $-3 Z$ and in $0.8 \%(5 / 655)$ the calculated $\mathrm{BMI}$ was lower than $-3 \mathrm{Z}$. BMI moderately increased in 


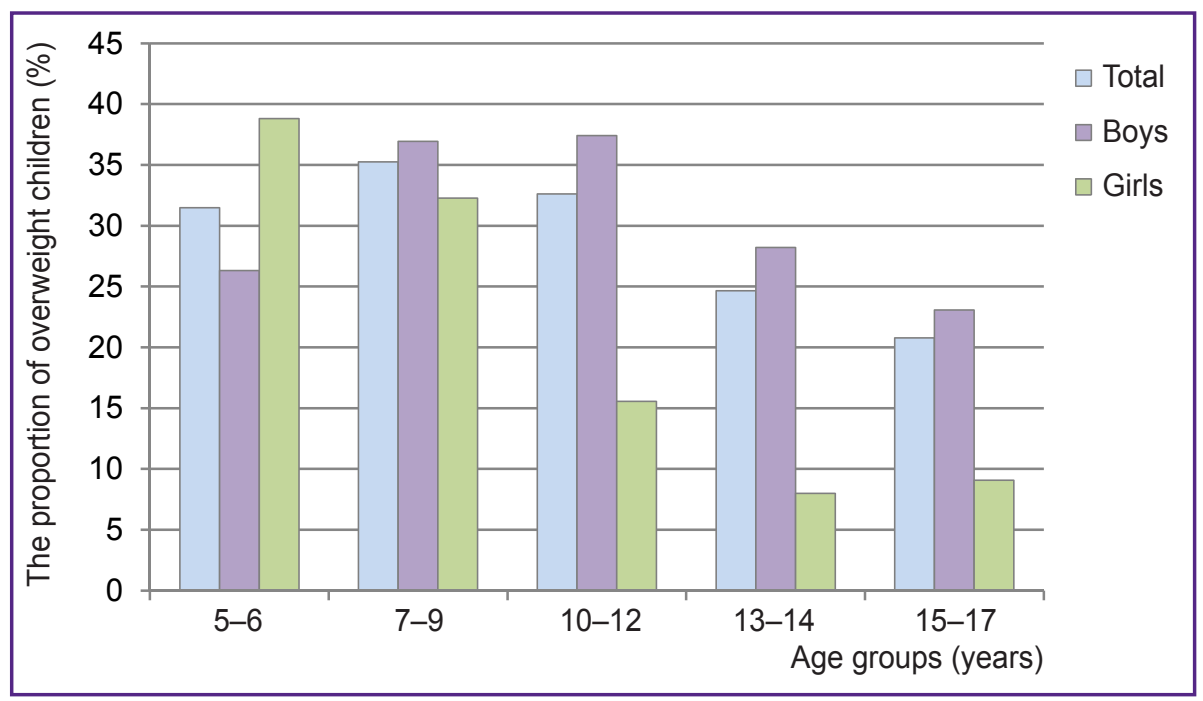

Figure 3. The proportion of overweight children among bronchial asthma patients at different age periods

the range from $+1 Z$ to $+2 Z$ was observed in $20.9 \%$ of patients (137/655), BMI significantly increased in the range from $+2 Z$ to $+3 Z$ was noted in $8.5 \%$ of patients $(56 / 655)$, excess BMI higher than $+3 Z$ was found in $0.9 \%$ of BA boys $(6 / 655)$.

The proportion of girls with normal BMI values amounted to $56.9 \%(132 / 232)$ and was similar to that in the group of boys. BMI was found to be reduced in $18.1 \%(42 / 232)$, of them $1.7 \%(4 / 232)$ had significant reduction to the range from $-2 Z$ to $-3 Z$ and in $0.9 \%$ $(2 / 232)$ the calculated BMI was lower than $-3 Z$ for the respective ages. $B M I$ moderately increased in the range from $+1 Z$ to $+2 Z$ was observed in $17.2 \%(40 / 232)$, significantly increased in the range from $+2 Z$ to $+3 Z$ in $6.5 \%(15 / 232)$, excess BMI higher than $+3 Z$ was found in $1.3 \%$ of BA girls $(3 / 232)$.

No gender differences in nutritional status of BA patients were established in the combined sample $\left(X^{2}=4.41 ; p=0.62\right)$. However, its analysis in different age groups demonstrates (See Table 5, Figure 3) that at primary school age there are actually no such differences, while in the period between 10 and 14 years of age nutritional status differences between boys and girls are statistically significant. At the same time, at preschool age, there is a tendency to an increase in the proportion of overweight children among girls compared to the situation with boys, while at primary school age the tendency changes to the opposite. In adolescent age groups the proportion of overweight children among boys is higher than that among girls. These differences are statistically significant at the age of 10-14 years and appear to be a tendency at the age of 15 to 17 years. In general, the change in the proportion of overweight children among boys has a pattern of a curve reaching the maximum at the age of $7-12$ years and declining to the minimum values by the age of 15 to 17 years. Among girls the proportion of overweight patients is maximum at pre-school age, further, as the age of children increases, a progradient decrease in that proportion is observed.

Fluctuations in the proportion of underweight children among BA patients are more monotonous, especially among boys. It is also noteworthy that the proportion of boys with elevated BMI and obesity is somewhat higher - 30.38\% (199/655) compared to girls $25 \%(58 / 232), x^{2}=2.16 ; p=0.14$. This may reflect the population trends because in the Russian population, as in the European region in general, the incidence of elevated BMI among boys is somewhat higher than among girls [10].

Evaluation of nutritional status in patients with bronchial asthma based on relative body mass index. Age and gender specific BMI, assessed according to Z-score system in children and adolescents, is a discrete parameter which cannot be used for quantitative analysis when continuous parameters are required. By contrast, RBMI is devoid of this drawback.

Table 6

Correlation dependence of relative body mass index on age in bronchial asthma patients

\begin{tabular}{|lcc}
\hline \multicolumn{1}{r}{ Group } & $\begin{array}{c}\text { Regressional expression } \\
\text { Linear regression }\end{array}$ & $\mathrm{p}$ \\
\hline All patients & $1.090-0.0002 \mathrm{t}$ & 0.085 \\
\hline Boys & $1.080-0.0001 \mathrm{t}$ & 0.550 \\
\hline Girls & $1.150-0.0010 \mathrm{t}$ & $<0.0001$ \\
\hline \multicolumn{3}{|c}{ Quadratic regression } \\
\hline All patients & $1.050+0.017 \mathrm{t}-0.005 \mathrm{t}^{2}$ \\
\hline Boys & $0.818+0.042 \mathrm{t}-0.00002 \mathrm{t}^{2}$ & 0.0040 \\
\hline Girls & $1.209-0.002 \mathrm{t}+0.004 \mathrm{t}^{2}$ & 0.0003 \\
\hline
\end{tabular}

$\mathrm{N}$ o t e. $\mathrm{t}$ - the age of patients in months. 
Besides, RBMI evaluation requires no grouping the patients by Z-score system, which facilitates calculations substantially and helps avoid sample size reduction often leading to compromised significance of results.

To identify the correlations between RBMI, age and gender parameters in children with BA properly, linear and polynomial regression analyses were carried out (Table 6). The presented results prove RBMI coefficient in BA boys to have no linear dependence on age. Girls show reverse dependence of RBMI coefficient on age, the correlations being rather weak, but statistically significant.

The analysis (Figure 4) showed, that the relationship between nutritional status assessed using RBMI coefficient and the patients' age in months has predominantly polynomial character, with correlations between RBMI coefficient and age in the polynomial regression being more well-marked in girls. In boys, RBMI elevation on the regression curve is observed at primary school age as compared to pre-school period, with RBMI subsequently declining by adolescence. By contrast, in girls, there is a trend of gradual decline in nutritional status parameters from pre-school age to adolescence. The same consistencies are demonstrated by the analysis of mean RBMI values in BA patients at different age periods (Table 7, Figure 5). The differences revealed in RBMI coefficient dynamics in proportion to the age of both boys and girls suggest the necessity to estimate the relationship between nutritional status and BA differentially in children of different genders.

RBMI provides the opportunity to evaluate nutritional status in children of different ages and genders correctly, which is shown in Table 8 . No statistically significant differences in RBMI levels have been found in children and adolescents with different $B A$ severities, $F=1.86$; $\mathrm{p}=0.135$.

To specify nutritional status distribution in patients with different BA severities, histograms of RBMI values were analyzed (Figure 6). Abscissae of all shown histograms have 15 RBMI value intervals 0.1 in width, the initial point of the first interval corresponds to RBMI=0.5. Thus, the points on the histogram abscissae are related
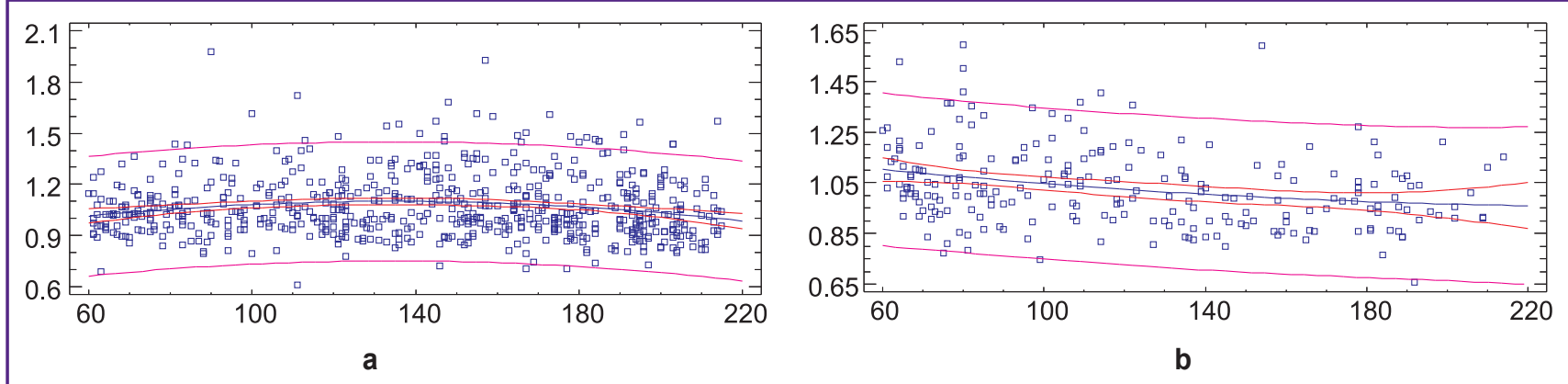

Figure 4. Quadratic dependence of relative body mass index coefficient on the age of bronchial asthma patients according to the results of regression analysis: (a) boys; (b) girls. Horizontal axis: age in months, vertical axis: relative body mass index

Table 7

Relative body mass index in different age and gender groups of patients with bronchial asthma

\begin{tabular}{|c|c|c|c|c|c|c|}
\hline \multirow{2}{*}{\multicolumn{2}{|c|}{ Groups }} & \multicolumn{5}{|c|}{ Age period (years) } \\
\hline & & $5-6$ & $7-9$ & $10-12$ & $13-14$ & $15-17$ \\
\hline \multirow{4}{*}{ All patients } & $\mathrm{n}$ & 162 & 173 & 208 & 142 & 202 \\
\hline & Mean & 1.06 & 1.08 & 1.07 & 1.08 & 1.03 \\
\hline & Standard deviation & 0.15 & 0.18 & 0.18 & 0.19 & 0.17 \\
\hline & \multicolumn{6}{|c|}{ ANOVA: $F=2.41 ; p=0.048 ;$ the Kruskal-Wallis test: $T=13.13 ; p=0.01$} \\
\hline \multirow{4}{*}{ Boys } & $n$ & 95 & 111 & 163 & 117 & 169 \\
\hline & Mean & 1.04 & 1.08 & 1.10 & 1.08 & 1.04 \\
\hline & Standard deviation & 0.12 & 0.19 & 0.19 & 0.19 & 0.18 \\
\hline & \multicolumn{6}{|c|}{ ANOVA: $F=2.88 ; p=0.022 ;$ the Kruskal-Wallis test: $T=11.68 ; p=0.02$} \\
\hline \multirow{4}{*}{ Girls } & $n$ & 67 & 62 & 45 & 25 & 33 \\
\hline & Mean & 1.08 & 1.06 & 0.99 & 0.97 & 0.97 \\
\hline & Standard deviation & 0.17 & 0.14 & 0.16 & 0.12 & 0.12 \\
\hline & \multicolumn{6}{|c|}{ ANOVA: $F=5.57 ; p=0.0003 ;$ the Kruskal-Wallis test: $T=2.08 ; p=0.0002$} \\
\hline Differences between boys & $T=-1.71$ & $\mathrm{~T}=0.8$ & $\mathrm{~T}=0.8$ & $\begin{array}{rl}T & =3.3 \\
n=0 & 001\end{array}$ & $\begin{aligned} T & =2.7 \\
n & =0.008\end{aligned}$ & $\begin{aligned} & T=2.2 \\
& n=0.03\end{aligned}$ \\
\hline
\end{tabular}




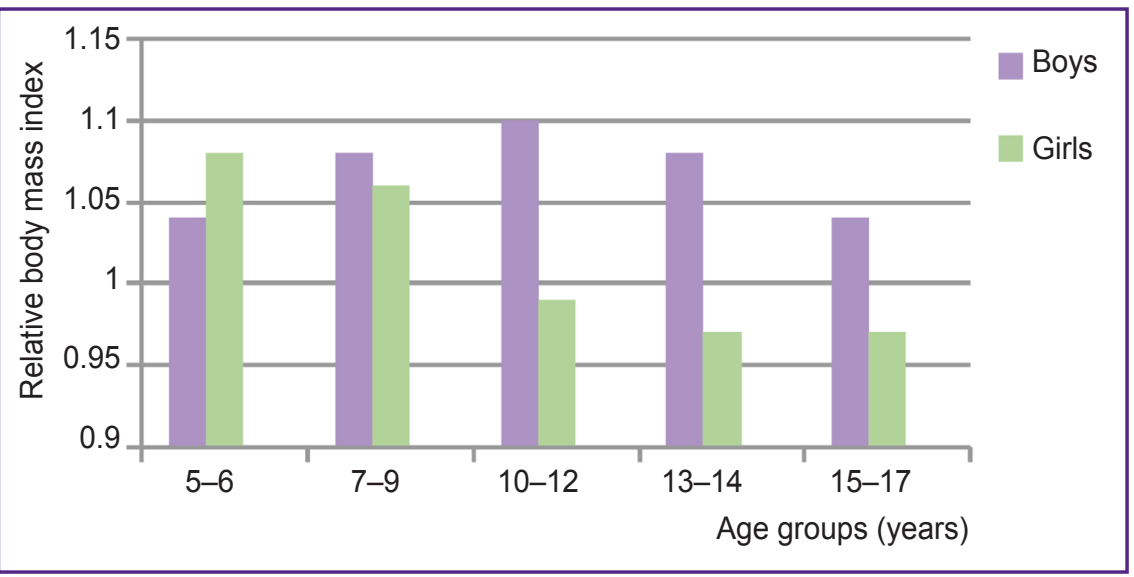

Figure 5. Mean values of relative body mass index in different age and gender groups of patients with bronchial asthma

Table 8

Gender-specific relative body mass index in patients with different degrees of bronchial asthma severity

\begin{tabular}{|c|c|c|c|c|}
\hline \multirow{2}{*}{ Parameters } & \multicolumn{4}{|c|}{ Bronchial asthma severity } \\
\hline & Intermittent & Mild persistent & Moderate persistent & Severe persistent \\
\hline \multicolumn{5}{|c|}{ Combined sample } \\
\hline Number of studies & 101 & 447 & 277 & 62 \\
\hline Mean & 1.046 & 1.051 & 1.08 & 1.051 \\
\hline Standard deviation & 0.16 & 0.17 & 0.19 & 0.18 \\
\hline $95 \% \mathrm{Cl}$ & $1.022-1.070$ & $1.040-1.063$ & $1.065-1.094$ & $1.020-1.082$ \\
\hline Skewness & 4.73 & 9.04 & 7.49 & 1.34 \\
\hline Kurtosis & 4.23 & 11.52 & 4.92 & -1.19 \\
\hline \multicolumn{5}{|c|}{ ANOVA: $F=1.86 ; p=0.14 ;$ the Kruskal-Wallis test: $T=2.92 ; p=0.40$} \\
\hline \multicolumn{5}{|c|}{ Boys } \\
\hline Number of studies & 84 & 328 & 196 & 47 \\
\hline Mean & 1.045 & 1.061 & 1.095 & 1.067 \\
\hline Standard deviation & 0.167 & 0.170 & 0.196 & 0.187 \\
\hline $95 \% \mathrm{Cl}$ & $1.018-1.072$ & $1.047-1.074$ & $1.077-1.112$ & $1.031-1.104$ \\
\hline Skewness & 4.44 & 7.71 & 6.48 & 0.62 \\
\hline Kurtosis & 4.03 & 10.23 & 4.12 & -1.18 \\
\hline \multicolumn{5}{|c|}{ ANOVA: $F=2.13 ; p=0.095 ;$ the Kruskal-Wallis test: $T=3.6 ; p=0.31$} \\
\hline \multicolumn{5}{|c|}{ Girls } \\
\hline Number of studies & 17 & 119 & 81 & 15 \\
\hline Mean & 1.050 & 1.026 & 1.04 & 0.99 \\
\hline Standard deviation & 0.135 & 0.157 & 0.162 & 0.140 \\
\hline $95 \% \mathrm{Cl}$ & $1.022-1.070$ & $1.040-1.063$ & $1.065-1.094$ & $1.020-1.082$ \\
\hline Skewness & 1.47 & 4.68 & 2.15 & 1.93 \\
\hline Kurtosis & 0.35 & 5.35 & -0.30 & 0.39 \\
\hline \multicolumn{5}{|c|}{ ANOVA: $F=0.49 ; p=0.58$; the Kruskal-Wallis test: $T=1.89 ; p=0.59$} \\
\hline
\end{tabular}

to RBMI by the formula RBMl $=0.1 n+0.5$, where $n$ is the number of the interval indicated on the horizontal axis of the histogram. In all studied histograms, median RBMI values fall within interval 6 . The interval, to the left of which there is RBMI decline, corresponds to number 4 . $\mathrm{RBMI}$ elevation starts to the right of interval 8.
Visual analysis shows that histograms of BA patients, in general and with reference to BA severity, have the maximum representation in the areas corresponding to normal BMl values. However, there is a shift in representation of histogram intervals to the values corresponding to overweight and obesity which are 


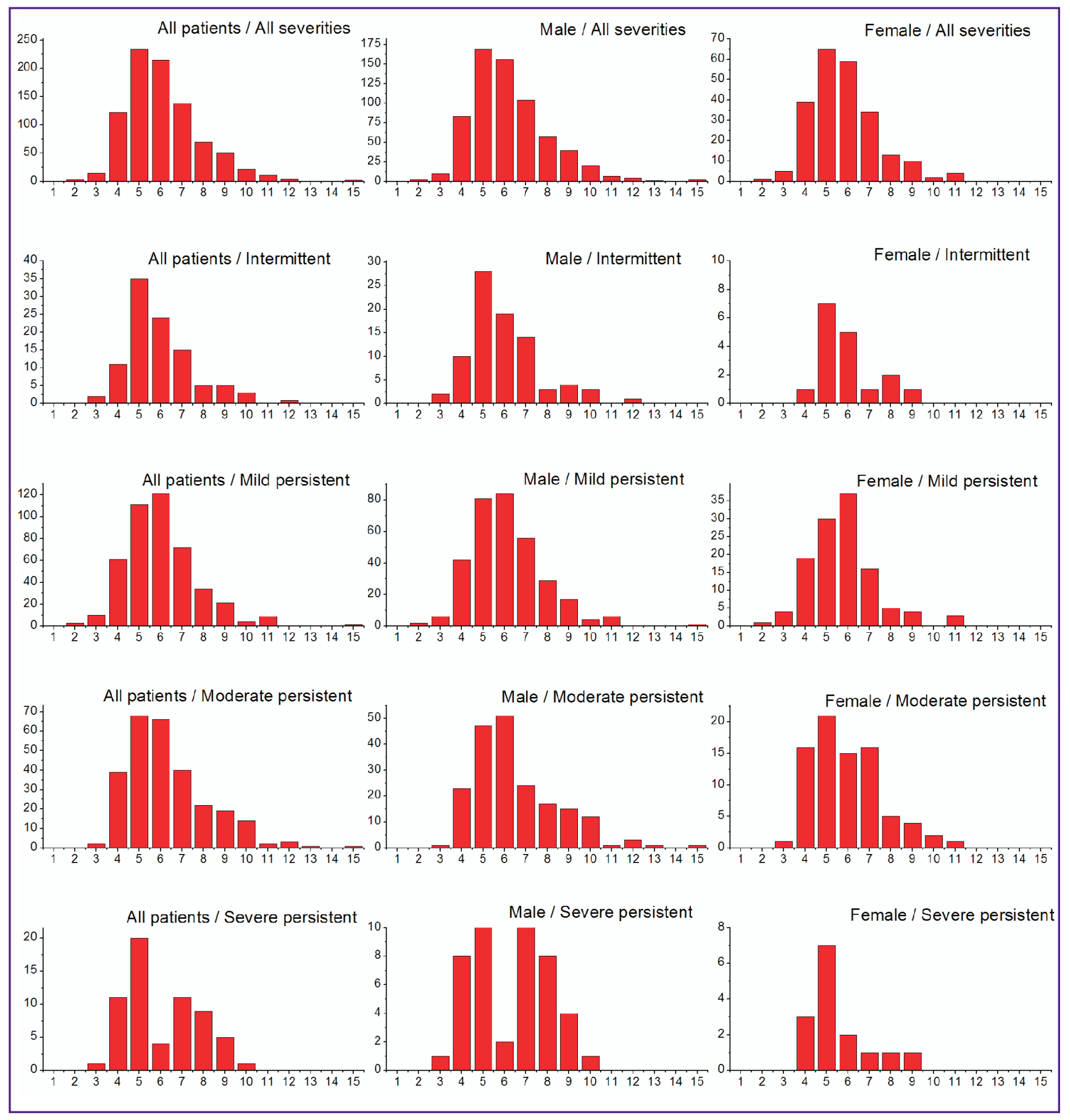

Figure 6. Distribution of patients with different values of relative body mass index coefficient within histogram intervals with regard to gender and bronchial asthma severity. Histogram intervals $1-15$ are on X-axis

more marked in male patients in this study. The revealed histogram skewness suggests that the cohort of patients under study is inhomogeneous and consists of several groups with different types of nutritional status. To identify these groups, the continuous nature of RBMI provides the possibility to decompose the available histograms into elementary Gaussian components. Here, the cumulative result of $y_{i}$ measurements is described by a function presenting the sum of Gaussian components $g_{i}$ with additional shift by constant value $y_{0}$ (baseline):

$$
y(x)=y_{0}+\sum_{i} g_{i}(x)
$$

Each Gaussian component $g_{i}$ is determined as

$$
g_{i}(x)=\sqrt{\frac{2}{\pi}} \frac{A_{i}}{\omega_{i}} e^{-\frac{2\left(x-x_{0 i}\right)^{2}}{\omega_{i}^{2}}}
$$


where $x_{0}$ - the center of Gaussian peak; $w_{i}-$ characteristic peak width; $A_{i}$ - peak area. Optimized parameters of each component are shown in Figure 7.

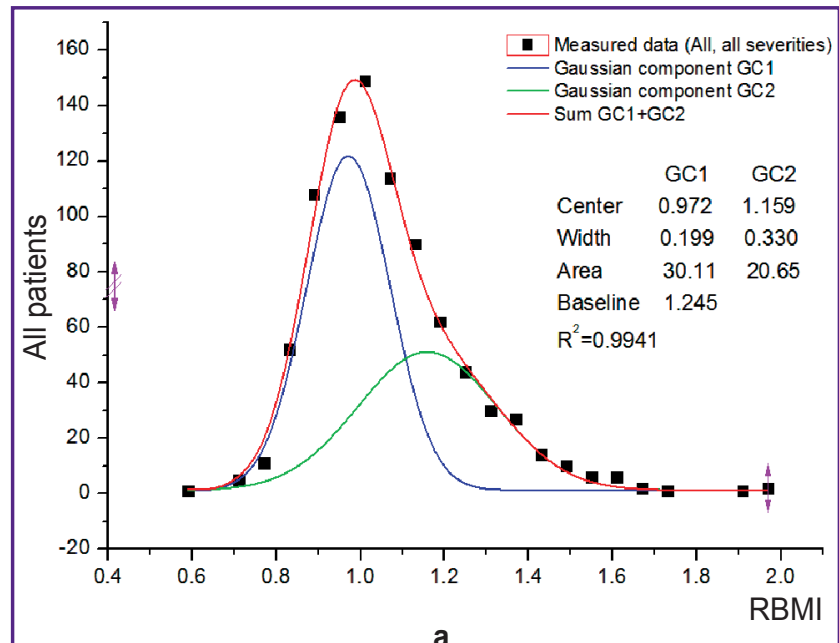

a

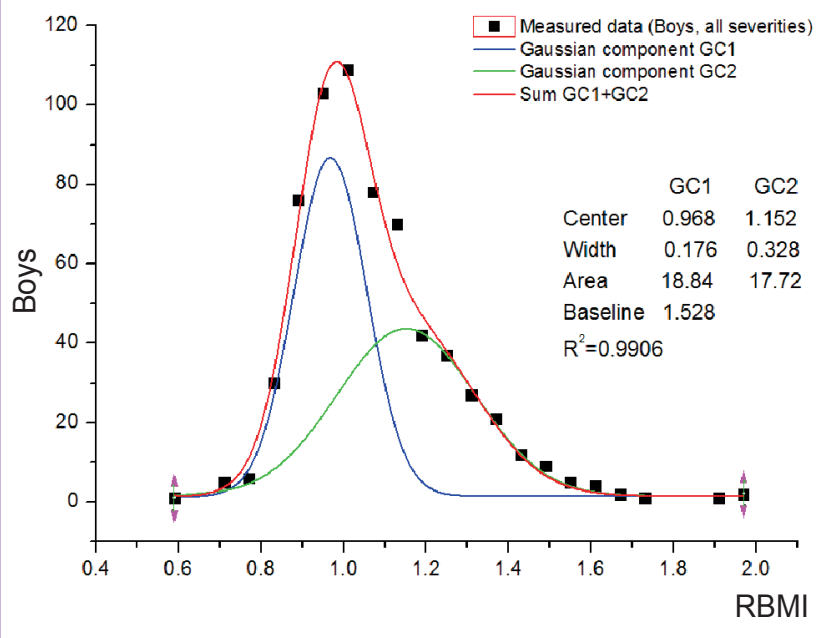

b

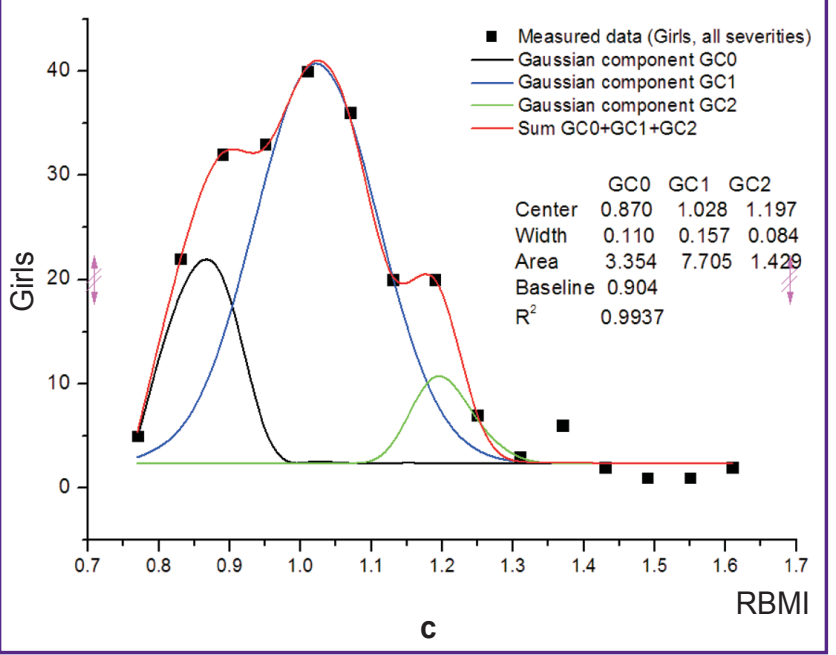

Figure 7. Decomposition of the top row histograms in Figure 6 into Gaussian components: (a) all patients; (b) boys; (c) girls. The horizontal axis shows relative body mass index (RBMI); the vertical axis shows the number of patients
The results of decomposing the histogram in Figure 7 (c) depended largely on the selection of histogram interval width due to relatively small number of measurements, so additional interpolation by cubic spline was performed prior to decomposing the histogram into Gaussian components. It should be noted that due to significantly smaller sample volume, the histogram pattern in the group of girls changes substantially with the interval width. Therefore, additional increase in sample volume is required to obtain more reliable results when girls are involved in the study.

The results of analysis of Gaussian components suggest that composition of two Gaussian curves is characteristic of the combined sample and the group of boys with BA (prevailing in the given sample of patients). In one curve, the peak actually corresponds to the median of normal RBMI values (0.97), and the peak of the second one is shifted in the direction of nutritional status elevation and equals 1.15. The histogram of female patients with BA has three major components, as a minimum: central component with the peak at $\mathrm{RBMI}=1.028$ (corresponds to normal nutritional status), a component with the peak close to $\mathrm{RBMI}=0.87$ (corresponds to low nutritional status) and a component with the peak at $\mathrm{RBMI}=1.2$, which corresponds to overweight.

Thus, mathematical decomposition of histograms suggests inhomogeneity in cohorts of BA patients in terms of nutritional status. However, to prove uniqueness or universality of these distributions for BA patients, further comparing the obtained results to nutritional status data of general population is required, for example, in the framework of case-control system, the obtained findings speak of high informative value of RBMI indicator compared to standard nutritional status characteristics.

Discussion. The proportion of overweight and obese BA children and adolescents amounted to $29.3 \%$ $(257 / 877)$ in this study, including those with obesity $9.1 \%(80 / 877)$. This exceeds the incidence of the given indicators among children and adolescents in the urban population of the studied region regardless of their pathology: overweight - 12.8\% (122/952), including those with obesity $-2 \%(19 / 952)$ [10].

When studying BMI as a tool for nutritional status assessment with the use of $X^{2}$, there were revealed the tendencies towards a decrease in normal body weight incidence and an increase in overweight and obesity incidence with increasing BA severity, $p=0.08$. This is consistent with the findings obtained by other authors who have demonstrated the influence of nutritional status on BA progression peculiarities in children [17-19].

Using RBMI as a tool for nutritional status assessment enables us to apply more accurate methods of statistical evaluation, including ANOVA technique. Using this technique demonstrates that the differences between the groups with different BA severities prove to be trends 
among boys, but they are not revealed among girls. This is consistent with the results obtained by Mai et al. [27] who found a notable association between rale and BMI in Swedish boys aged 11 to 13 as opposed to girls, though this association was statistically insignificant. Joseph et al. [28] also noticed an association between overweight and BA progression peculiarities in boys as opposed to girls. At the same time, according to Chinn [29], there is no conclusive evidence proving the presence of gender differences in association between asthma and obesity among BA children and adolescents.

In the combined sample of our research, no distinct gender differences were found in the incidence of children with normal BMI and BMI different from the norm among BA patients of child and adolescent age. Nevertheless, it was established that at some age periods, the proportion of patients with nutritional status abnormalities among boys and girls differs statistically significantly and, in general, the proportion of overweight patients among boys tends to exceed that among girls. The obtained findings may reflect the population trends: investigation undertaken by Dedov et al. [10] shows that in Russian population, in general, overweight among adolescents (12-17 years) occurs in $11.0 \%$ of boys (of them obesity in $2.5 \%$ ) and in $7.7 \%$ of girls (of them obesity in $1.6 \%$ ). In our case, the most frequent overweight incidence among BA patients of child and adolescent age was characteristic of pre-school, primary school and prepubertal ages. A statistically significant increase in the proportion of BA patients with normal body weight and a simultaneous decrease in the proportion of overweight children are observed among those aged 13 years and over. On the one hand, this questions the restriction of movement in patients with asthma as the primary cause of the increase in overweight and obesity incidence, since the proportion of overweight children decreases with age. On the other hand, the revealed trends may reflect population patterns. It is reported in the above-cited paper by Dedov et al. [10] that there is a decrease in the proportion of overweight children with age: in both girls and boys, overweight incidence is maximum at the age of $12-13$ years, amounting to 12.1 and $15.5 \%$, respectively. The proportion of overweight children decreases up to $7.7 \%$ by the age of 17 years. According to these authors, the periods of critical weight gain are 9-12 years in girls and $7-13$ years in boys, which is determined by natural laws of puberty.

The use of RBMI helps to reveal common patterns of cohort formation according to nutritional status among BA children and adolescents. For instance, decomposition of histograms into Gaussian components evidences the presence of two major subgroups among boys in terms of their nutritional status: with normal, low and excessive body weight, and three subgroups among girls: with normal, low and excessive body weight. This is in line with the opinion about the presence of BA phenotypes associated with nutritional status changes and overweight, which was confirmed by metabolomic research conducted by Maniscalco et al. [30]. The presence of a subgroup of female BA patients with low nutritional status also seems to be an important factor, which determines the expedience of studying clinical and other characteristics, including metabolomic aspects, in this subgroup.

The conducted study shows that, firstly, RBMI is a parameter providing the possibility to avoid timeconsuming distribution of patients among Z-score tables. Secondly, it gives the possibility to use RBMI as a single continuous variable allowing significant simplification of many types of statistical analysis, for example, decomposition of histograms into Gaussian components. Thirdly, in many cases, introducing a consolidated parameter helps to avoid sample volume reduction when dividing the patients into age-gender groups and to enhance statistical significance of measurements.

It should be noted that in case of adult patients, RBMI role will not be so remarkable, as their nutritional status almost does not change with age. However, when estimating nutritional status in children and adolescents, the use of RBMI seems to be an important tool as quantile values of nutritional status parameters undergo considerable changes in such patients and using BMI and Z-score indices leads to the difficulties described above. This speaks of a potential relationship between nutritional status changes and asthma and the need for more detailed study of the given cohort of patients in terms of phenotypic and endotypic properties: investigating functional indices, the patterns of dynamics of inflammation markers, metabolomic and other markers [31-33]. The group of patients with low BMI parameters is absolutely worth paying attention to. The proportion of such patients is maximum among the girls: $18.1 \%$. This necessitates in-depth studying the given group of patients.

Conclusion. Comparing the possibilities of studying nutritional status and its relationship with bronchial asthma in children and adolescents using two parameters - the standard nutritional status indicator based on BMI and its value assessed using Z-scores as recommended by $\mathrm{WHO}$ and a new parameter, RBMI, representing the ratio of BMI to gender- and agespecific median BMI value recommended by WHO shows that the use of RBMI for evaluating BA children helps to significantly facilitate clinical data analysis and obtain new data remaining unavailable when standard parameters are applied.

Study Funding. This work was partially supported by projects 156150 and 240844 CONACYT, Mexico, funded by the subsidy of Russian Government Program of Competitive Growth of Kazan Federal University.

Conflicts of Interest. The authors have no conflict of interests to disclose.

\section{References}

1. GINA. Global Strategy for Asthma Management and Prevention. 2016. 
2. Rabe K.F., Adachi M., Lai C.K., Soriano J.B., Vermeire P.A., Weiss K.B., Weiss S.T. Worldwide severity and control of asthma in children and adults: the global asthma insights and reality surveys. J Allergy Clin Immunol 2004; 114(1): 40-47, https://doi.org/10.1016/j.jaci.2004.04.042.

3. Eliseeva T.I., Balabolkin I.I. Modern technologies of bronchial asthma control in children (review). Sovremennye tehnologii $v$ medicine 2015; 7(2): 168-184, https://doi. org/10.17691/stm2015.7.2.21.

4. Braido F., Brusselle G., Guastalla D., Ingrassia E., Nicolini G., Price D., Roche N., Soriano J.B., Worth H. Determinants and impact of suboptimal asthma control in Europe: The International Cross-Sectional and Longitudinal Assessment on Asthma Control (LIAISON) study. Respir Res 2016; 17(1): 51, https://doi.org/10.1186/s12931-016-0374-z.

5. Krasilnikova S.V., Eliseeva T.I., Shakhov A.V., Prakhov A.V., Balabolkin I.I. Video endoscopic method of estimation state of nasal and pharyngonasal cavity in children with bronchial asthma. Sovremennye tehnologii $v$ medicine 2012; 3: 41-45.

6. Sheehan W.J., Phipatanakul W. Difficult-to-control asthma: epidemiology and its link with environmental factors. Curr Opin Allergy Clin Immunol 2015; 15(5): 397-401, https:// doi.org/10.1097/aci.0000000000000195.

7. Schatz M., Zeiger R.S., Zhang F., Chen W., Yang S.J., Camargo C.A., Jr. Overweight/obesity and risk of seasonal asthma exacerbations. J Allergy Clin Immunol Pract 2013; 1(6): 618-622, https://doi.org/10.1016/j.jaip.2013.07.009.

8. Weinmayr G., Forastiere F., Büchele G., Jaensch A., Strachan D.P., Nagel G.; ISAAC Phase Two Study Group. Overweight/obesity and respiratory and allergic disease in children: international study of asthma and allergies in childhood (ISAAC) phase two. PLoS One 2014; 9(12): e113996, https://doi.org/10.1371/journal.pone.0113996.

9. WHO. Obesity and overweight. Informatsionnyy byulleten' 2016. URL: www.who.int/mediacentre/factsheets/ fs $311 /$ ru/.

10. Dedov I.I., Mel'nichenko G.A., Butrova S.A., Savel'eva L.V., Bodaveli O.V., Buydina T.A., Vikhareva M.V., Vorob'eva V.A., Esayan R.M., Zaykova I.O., Kamshilova K.A., Kiseleva N.G., Kovarenko M.A., Mikhaylova E.G., Oorzhak U.S., Panfilova V.N., P'yankova E.Yu., Smetanina S.A., Sergeeva N.E., Suplotova L.A., Taranushenko T.E., Kharitonova N.E., Chebotnikova T.V., Chernyak I.Yu., Shalennaya I.G., Yanovskaya M.E. Obesity among teenagers in Russia. Ozhirenie i metabolizm 2006; 4: 30-34.

11. Ahmedova R.M., Sofronova L.V., Trefilov R.N. Prevalence and gender characteristics of obesity in adolescents in the city of Perm. Voprosy sovremennoy pediatrii 2014; 13(5): 37-41.

12. Beuther D.A. Obesity and asthma. Clin Chest Med 2009; 30(3): 479-488, https://doi.org/10.1016/j. ccm.2009.05.002.

13. Liu Y., Pleasants R.A., Croft J.B., Lugogo N., Ohar J., Heidari K., Strange C., Wheaton A.G., Mannino D.M., Kraft M. Body mass index, respiratory conditions, asthma, and chronic obstructive pulmonary disease. Respir Med 2015; 109(7): 851859, https://doi.org/10.1016/j.rmed.2015.05.006.

14. Bibi H., Shoseyov D., Feigenbaum D., Genis M., Friger M., Peled R., Sharff S. The relationship between asthma and obesity in children: is it real or a case of over diagnosis? J Asthma 2004; 41(4): 403-410.

15. Liu P.C., Kieckhefer G.M., Gau B.S. A systematic review of the association between obesity and asthma in children. J Adv Nurs 2013; 69(7): 1446-1465, https://doi.org/10.1111/ jan.12129.

16. Cassol V.E., Rizzato T.M., Teche S.P., Basso D.F., Centenaro D.F., Maldonado M., Moraes E.Z., Hirakata V.N., Solé D., Menna-Barreto S.S. Obesity and its relationship with asthma prevalence and severity in adolescents from southern Brazil. J Asthma 2006; 43(1): 57-60, https://doi. org/10.1080/02770900500448597.

17. Michelson P.H., Williams L.W., Benjamin D.K., Barnato A.E. Obesity, inflammation, and asthma severity in childhood: data from the National Health and Nutrition Examination Survey 2001-2004. Ann Allergy Asthma Immunol 2009; 103(5): 381-385, https://doi.org/10.1016/s10811206(10)60356-0.

18. Forno E., Acosta-Pérez E., Brehm J.M., Han Y.Y., Alvarez M., Colón-Semidey A., Canino G., Celedón J.C. Obesity and adiposity indicators, asthma, and atopy in Puerto Rican children. J Allergy Clin Immunol 2014; 133(5): 13081314.e5, https://doi.org/10.1016/j.jaci.2013.09.041.

19. Ford E.S. The epidemiology of obesity and asthma. J Allergy Clin Immunol 2005; 115(5): 897-909, https://doi. org/10.1016/j.jaci.2004.11.050.

20. Dixon A.E., Shade D.M., Cohen R.I., Skloot G.S., Holbrook J.T., Smith L.J., Lima J.J., Allayee H., Irvin C.G., Wise R.A. Effect of obesity on clinical presentation and response to treatment in asthma. J Asthma 2006; 43(7): 553558, https://doi.org/10.1080/02770900600859123.

21. Ginde A.A., Santillan A.A., Clark S., Camargo C.A. Jr. Body mass index and acute asthma severity among children presenting to the emergency department. Pediatr Allergy Immunol 2010; 21(3): 480-488, https://doi.org/10.1111/j.13993038.2009.00911.x.

22. Willeboordse M., Kant K.D., Tan F.E., Mulkens S., Schellings J., Crijns Y., Ploeg L., van Schayck C.P., Dompeling E. A multifactorial weight reduction programme for children with overweight and asthma: a randomized controlled trial. PLoS One 2016; 11(6): e0157158, https://doi.org/10.1371/ journal.pone.0157158.

23. Pechkurov D.V., Voronina E.N., Poretskova G.Yu. Features of physical development, eating behavior and quality of life of children with bronchial asthma. Prakticheskaya meditsina 2013; 6(75): 122-126.

24. GINA. Global Strategy for Asthma Management and Prevention. 2006.

25. GINA. Global Strategy for Asthma Management and Prevention. 2007.

26. GINA. Global Strategy for Asthma Management and Prevention. Global Initiative for Asthma (GINA). 2011.

27. Mai X.M., Nilsson L., Axelson O., Bråbäck L., Sandin A., Kjellman N.I., Björkstén B. High body mass index, asthma and allergy in Swedish schoolchildren participating in the International Study of Asthma and Allergies in Childhood: Phase II. Acta Paediatr 2003; 92(10): 1144-1148, https://doi. org/10.1080/08035250310005666.

28. Joseph C.L., Havstad S.L., Ownby D.R., Zoratti E., Peterson E.L., Stringer S., Johnson C.C. Gender differences in the association of overweight and asthma morbidity among urban adolescents with asthma. Pediatr Allergy Immunol 2009; 20(4): 362-369, https://doi.org/10.1111/j.13993038.2008.00803.x.

29. Chinn S. Obesity and asthma. Paediatr Respir Rev 2006; 7(3): 223-228, https://doi.org/10.1016/j.prrv.2006.04.007. 
30. Maniscalco M., Paris D., Melck D.J., D’Amato M., Zedda A., Sofia M., Stellato C., Motta A. Coexistence of obesity and asthma determines a distinct respiratory metabolic phenotype. J Allergy Clin Immunol 2016, https://doi. org/10.1016/j.jaci.2016.08.038.

31. Eliseeva T.I., Knyazeva E.V., Bochkova Y.S., Kononova S.V., Geppe N.A., Balabolkin I.I. Spirographic parameters and their change in bronchial patency variability tests in control level assessment of bronchial asthma in children. Sovremennye tehnologii v medicine 2013; 5(4): 94-101.
32. Eliseeva T.I., Kulpina Yu.S., Soodaeva S.K., Kubysheva N.I. Content of the nitrogen oxide metabolites in a condensate of exhaling air in children with a bronchial asthma control different level. Sovremennye tehnologii $v$ medicine 2010; 4: 42-47.

33. Eliseeva T.I., Knyazeva E.V., Geppe N.A., Balabolkin I.I. The relationship of spirographic parameters and bronchial responsiveness with asthma control level in children (according to ACQ-5 and ACT-C Data). Sovremennye tehnologii $v$ medicine 2013; 5(2): 47-52. 